\title{
Observations on the Use of Plastazote Insoles in England
}

\author{
W. H. JOPLING \\ Consultant Le prologist \\ Hospital for Tropical Diseases, London, N.W.1, England
}

\begin{abstract}
The author reports the generally good results observed in 14 patients suffering from plantar ulceration, in most cases associated with arrested lepromatous leprosy, after their footwear had been expertly fitted with Plastazote insoles. The after-treatment of healed plantar ulcer is also briefly outlined.
\end{abstract}

Since the beginning of 1968, when Mr. Tuck drew my attention to the possible use of Plastazote for the prevention and cure of plantar ulceration, I have referred 14 leprosy patients to him. They were under treatment as out-patients and all had previously been fitted with orthopaedic shoes made of leather. Details are given in Table 1 .

TABLE 1

To show effect of Plastazote insoles on plantar ulceration (established or threatened)

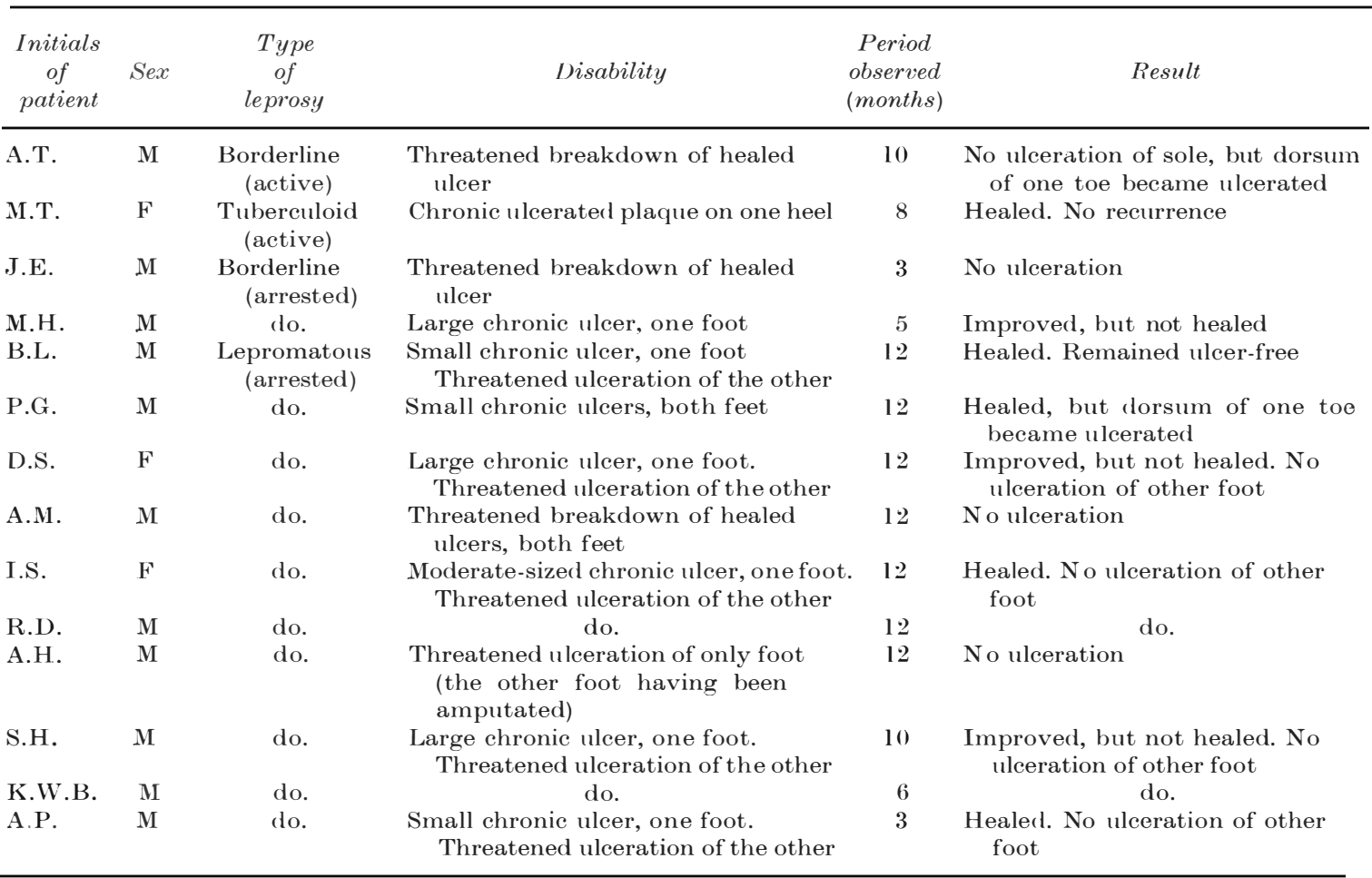

\footnotetext{
*Received for publication 29 April, 1969.
} 
It is interesting to note that, in my work in England, lepromatous leprosy is far more important than tuberculoid or borderline leprosy as a cause of plantar ulceration, even though lepromatous patients constitute only one-third of the total number of leprosy patients under my care. The 10 lepromatous patients in this series had been under treatment for 10 years or more and could be classified as arrested cases; even so, they all had "glove and stocking" anaesthesia which had first appeared in the later stages of treatment and which, in some of them, was still increasing. The Plastazote insoles supplied by Mr. Tuck were placed inside the orthopaedic shoes with which the patients had previously been supplied, and this probably accounted for the fact that 2 of the patients developed ulceration on the dorsa of their toes as a result of the toes being rubbed against the uppers. It is hoped that in future this complication will be avoided by making new orthopaedic shoes, with good clearance for the toes, when fitting Plastazote insoles.

These insoles were effective in 10 out of 14 cases $(70 \%)$ and partially effective in 4 . In each case local treatment was unchanged after fitting of the insoles, normal activities were continued, and the only other treatment consisted of antileprosy drugs by mouth. An important part of local treatment was to scrape away the callus which formed over a healed ulcer or over a potential ulcer site; this had to be done regularly, and the patients were encouraged to soak their feet daily and to scrape with pumice while the callus was still soft. The soggy white skin which tended to form around the chronic ulcers was cut away with sterile scissors to allow healing from below. Probably an even higher success rate could be achieved by replacing leather soles by rigid ones, thus avoiding the damaging pressure on the metatarsal heads which occurs in walking when the rear foot thrusts the body forward at each step. It is significant that the partial failures in this series occurred in patients who had large ulcers which had been present for years; future policy in such cases will be to heal the ulcers by bed-rest or by the use of a "walking plaster" before fitting the Plastazote insoles. 